\title{
Influence of Tourism on Economic Development in Asian Countries
}

\author{
Wen-Chuan FU1 \\ Chia-Jui PENG ${ }^{2}$ \\ Tzu-Yi YANG ${ }^{3}$
}

\begin{abstract}
Although the tourism industry has recorded the lowest pollution, it significantly contributes to the global economy. Therefore, many countries have spent great efforts in promoting their tourism industry to support their entire economic development. This article considers factors related to the relationship between national economic growth and international entry tourism for 11 Asian countries to investigate the existence of the cross-sectional difference between these countries.

Results show that exchange rate fluctuation is an alternative factor affecting economic growth risk, and common slope exists between countries. Moreover, international entry tourist headcount and income show differential slope in some countries, implying that these factors affect the economies of different Asian countries differently.
\end{abstract}

KEYWORDS: tourism receipts, GDP, exchange rates, tourist arrivals

JEL CLASSIFICATION: $L 83, Z 32, F 63$

\section{INTRODUCTION}

In recent years, scholars focused on tourism-related topics rapidly developed in many cities around the world, given that this industry drives the economic activity of a country. Along with the rapid development in cities, governments' investment in the infrastructure of economy and environment has improved the standard of living of residents in cities of many developing countries. Therefore, the tourism industry is also known as the sunrise industry, which is especially true in many Asian countries with tourism as their focus. In these countries, the increase of tourist entry headcount has become a significant factor of the national economic growth (Han et al., 2019). Given the benefits acquired from consumption of entry of foreign tourists for natural scenic spot and humanistic, historical and ecological forms of tourism, many developing countries, in the economic development topics, have turned tourism entry as governments' key implementation item. Moreover, many countries with featured scenery sites have listed tourism industry as one of the key targets for economic development due to the development brought by this industry (Yang et al., 2019).

In accordance with the statistical data reported by the World Travel \& Tourism Council (WTTC), in 2019, the tourism industry accounted for approximately $10.3 \%$ of the global GDP. It had brought in 330 million job opportunities, indicating that one out of ten in the world's population is in such related job. Its economic effectiveness has also shown a spillover effect to commercial and investment perspectives, and amongst the global service trade

\footnotetext{
${ }^{1}$ Chung Yuan Christian University, chyuan650731@cycu.org.tw

${ }^{2}$ Chung Yuan Christian University, pcrabao@gmail.com

${ }^{3}$ Ming Chi University of Technology, tyyang@mail.mcut.edu.tw, corresponding Author
} 
export, the tourism industry has contributed over one-fourth (28.3\%). WTTC also reported that, in 2019, the tourism department had an output growth rate of approximately $3.5 \%$, which was higher than the global GDP growth rate of $2.5 \%$. In the past five years, the department has addressed almost one out of four job vacancies, and all these data have shown that the tourism industry will continue to provide a momentum to the global economic growth.

To optimise the effect between economic growth and tourism topic, scholars used comparison and analysis models to quantify the relationship between economic growth and tourism. The results showed a significant relationship between economic growth and foreigners' tourism entry (Li, et al., 2019). Previous studies also used a descriptive statistical method to investigate the influential result between the two. In other words, they used economic growth monitoring and the behaviour of actual tourism population for comparison and evaluation. Although the traditional method of using tourism information can monitor that the increase in tourist arrival can lead to national economic growth, it still requires high degree use of computer information for calculation and comparison. This method is relatively complicated, and it is not a good modern statistical method (Zhang \& Zhang, 2018). Given the rapid change of global economy and the difference of tourism encouragement policy and politicaleconomic environment amongst different tourism countries, the project of expansion of international tourism entry adopted by each country for enhancing economic growth may vary depending on many national policies. Therefore, further studies on the differential factor are necessary.

In recent years, Asian countries are always a new star for tourism, and their entry tourist arrival increases annually. Each country has a continuous increase in infrastructure and tourism investment to enhance the tourism value effectively and create high GDP. Considering that tourism population flow may have the characteristic of localisation, using Asian countries as research targets has its representative meaning. In Asian countries, the population size and flow of tourist arrival are relatively major, and thus investigations can include developed and developing countries as research targets. This article focuses on the commonality and difference between economic growth and tourism in Asian countries.

Previous research pointed out a substantial influential power between economic development and tourism (Aleemi \& Qureshi, 2015; Bădulescu et al., 2018; Selimi et al., 2017; Tugcu, 2014). When a country has active economic development, it can attract foreign tourists to visit and promote continuous tourism development. Rich and perfect tourism resources can also increase tourism value (Aleemi \& Qureshi, 2015; Akinboade \& Braimoh, 2010; Olabisi, 2018; Yalçinkaya et al., 2018). These factors attract governments of many countries to have a fast investment in hardware and software in the tourism industry, which brought up the output effect of supply chains of related industries to create more foreign exchange income. The fluctuation in the foreign exchange rate, to the tourism market, reflects the consumption behaviour of tourists and derives their willingness to visit. In turn, it affects national economic development. The increase in entry headcount and tourism income may also urge the infrastructure construction and tourism investment in the host country, and the economic growth represents the trend of change of the overall economic activity. It is an important index used to evaluate the economic activity of a country.

In this article, we use the panel data model to investigate the overall influential effects between variables and understand the relationship amongst GDP growth and tourism income, growth of entry tourist arrival and foreign exchange fluctuation in Asia. We also conduct a Wald test. This test can determine the difference in the overall effect of tourism variable on 
the GDP of each country. In other words, we further analyse the meaning of the individual slope of each variable of each country. The governments and authorities handling the tourism industry of each country can use this study as a reference to understand the overall trend and hopefully make an improvement on individual difference of each country to catch the economic development effectiveness brought by tourism.

\section{LITERATURE REVIEW}

Many economic factors can explain international tourism behaviour. In recent years, scholars focused on tourism income and the economy. For example, Selimi et al. (2017) applied panel data, random effect and fixed-effect models to test and investigate the correlation amongst economic growth, per capita income, tourist headcount, tourism income, the stock of foreign direct investment, export and governments' expenditure. They proved that for countries in the Balkan area, tourism had a positive and significant effect on economic growth. Yalçinkaya et al. (2018) conducted panel data analysis to investigate the correlation amongst GDP, fixed asset investment tourism income and employment labour force. They found that international tourism income had an aggressive and significant influence on the economic growth of 20 countries with the highest incomes. In addition, Ardra and Martawardaya (2017) applied panel data test to investigate eight countries in the Association of Southeast Asian Nations (ASEAN). They showed that GDP had a positive and significant influence on tourist arrival but a negative and significant influence on tourism income. Similarly, Bădulescu et al. (2018) investigated the correlation between tourism income, tourist arrival and GDP. They concluded that in Central and Eastern Europe, tourism could stimulate economic growth, and economic development could support tourism development. Correspondingly, Kılıç and Bayar (2014) applied a co-integration model to investigate the relationship between fluctuations in the foreign exchange rate, tourism income and tourism expenditure in Turkey. They observed that fluctuation in foreign exchange rate might affect tourism income and tourism expenditure and found a positive long-term relationship between fluctuations in the foreign exchange rate, tourism income and expenditure. Likewise, Kadir and Karim (2012) applied panel time-series approach and panel causality test to investigate the cause-and-effect relationship between the tourism industry and economic growth for entry of ASEAN into Malaysia. They found a relationship between international tourism income and economic growth, from international tourism income to actual economic growth, indicating a short and long-term relationship between the two. Kum et al. (2015) applied a panel co-integration model to investigate the correlation amongst international tourist headcount, labour force, capital formation and GDP. They showed a long-term relationship between the tourist headcount and GDP of 11 countries under study, such as Japan and Korea, and tourist headcount had a positive influence on GDP growth. They also observed a one-way causality from economic growth to the tourism industry and proven the economy-driven tourism industry growth hypothesis. Tugcu (2014) studied the correlation amongst per capita GDP, tourism income and tourism expenditure in peripheral countries of Mediterranean Sea, and the results showed a positive influence between tourism income and economic growth in European countries but an insignificant and negative influence in Asian and African countries.

Comparatively, Aleemi and Qureshi (2015) investigated the relationship between GDP and tourism income, and the result showed that tourism income had an aggressive and significant influence on the economic growth of Pakistan. Moreover, they found that tourism could create employment opportunities, and it was a source of foreign exchange income and GDP. Olabisi, (2018) explored the correlation between tourism expenditure, tourism income, labour force and gross capital formation. The results showed that in the panel data from 15 western African 
countries, tourism expenditure and tourism income had no aggressive and significant influence on economic growth. Yazdi (2019) applied the RDL model and cause-and-effect relationship to test and investigate the correlation amongst per capita GDP, tourism income, fixed asset formation, human capital and family consumption expenditure for Iranians. The results showed that economic growth and tourism income were consistent. Scholars could also use the above finding to estimate the short and long-term relationship between economic growth and its variable, implying a one-way causality relationship from tourism to economic growth. Wang (2009) studied the correlation amongst international entry tourist headcount, GDP, CPI (tourism price), the fluctuation of exchange of foreign currency to US dollars (EX), oil price (transport cost) and tourism self-delay period. The results showed a significant relationship between tourist headcount growth and foreign exchange rate fluctuation for Japanese visitors to Taiwan. Akinboade and Braimoh (2010) analysed the contribution from international tourists on the economy of South Africa. They used a multivariate VAR model for analysis and took GDP, international tourism income, real effective exchange rate and export as variables. They found a positive and significant relationship between tourism income and foreign exchange rate but an insignificant relationship between tourism income and GDP. Nanthakumar et al. (2013) conducted a structural breaking and dynamic cointegration test to investigate the correlation amongst tourist arrival, CPI and foreign exchange rate. They found a significant and positive relationship between entry tourist arrival and foreign exchange rate from Singapore, Indonesia and Thailand to Malaysia. Said et al. (2013) used an auto-regression model to investigate the correlation amongst tourist arrival, foreign exchange rate and inflation. They found a significant and positive correlation between tourist arrival and foreign exchange rate. Tung (2019) investigated the correlation between tourist arrival and exchange rate in Vietnam. The results showed that the exchange rate had a positive influence on foreign tourist arrival.

The above literature confirmed that tourist arrival, tourism income and the exchange rate influenced the economic development of many countries. However, scholars obtained different results in different areas or countries. In the present article, we conduct a deep study in Asia. Traditional tourism studies mostly adopted a panel data model to investigate the common result between variables. In practice, a real difference exists in different countries in the same area due to varying political factors, geographical factors, territory characteristic and economic scale. Hence, the same result was not necessarily able to explain the situations in all the countries, and the improvement opinion does not apply to all cases. After our panel data model generates consistent results, we will further investigate whether a difference exists amongst individual countries to disclose the relationship of difference and similarity between economic development and tourism for different countries. Consequently, we can provide efficient suggestions close to the truth for a country.

\section{METHODOLOGY}

\subsection{Empirical Model}

We observed that when studies adopt panel data method for empirical analysis, two models were available: fixed effect model and random effect model. The former is also known as the least squares dummy variable model. Previous studies usually introduced dummy variables, such as area fixed effect and time fixed effect, into this model. With area fixed effect, when we control all other independent variables, each area will, due to its area characteristic, cause a long-term and fixed effect on the dependent variables of the past years in the area. The influence will not be different due to time. With time fixed effect, when we control all other independent variables, it will cause short term and fixed influence on the dependent variables 
of different areas of that year due to the characteristic possessed by a certain year. The influence will not be different due to different areas. The latter is also known as the error component model, and the area-specific fixed effect and the time-specific fixed effect it represents are the same as that of the fixed-effect model. In this model, scholars focused on the overall relationship of the population instead of the difference amongst different units. In other words, differences exist in each observation unit. This model also assumes that individual difference within the population is small. Thus, previous studies adopted a random sampling method to acquire the sample variable. We could generally judge the selection of the fixed-effect model and random effect model from the Lagrange multiplier test or the Hausman test. In the present article, we used Hausman test to decide if the selection of the fixed-effect model is better than the selection of the random effect model. To inspect the influence of the independent variables on the dependent variable in regression estimator and identify if a difference exists along with the individual group, we further used the Wald test to judge.

We expressed our Wald test hypotheses as follows:

$\mathrm{H}_{0}: \mathrm{a}_{1 \mathrm{k}}=\mathrm{a}_{2 \mathrm{k}}=\ldots=\mathrm{a}_{\mathrm{nk}}, \mathrm{k}=2, \ldots, \mathrm{k}$.

$\mathrm{H}_{1}: \mathrm{a}_{1 \mathrm{k}}, \mathrm{a}_{2 \mathrm{k}}, \ldots, \mathrm{a}_{\mathrm{nk}}$ not exactly equal, $\mathrm{k}=2, \ldots, \mathrm{k}$.

If our results failed to support the null hypothesis, then the influence of specific explanatory variable on the explained variable would change along with the difference of cross-section. At this moment, we coined the adopted estimation method as the panel data model of the differential slope.

In this study, we adopted a panel data research method to investigate the influence of international entry tourist arrival, international entry tourism income and exchange rate on economic development of different countries. We set up an empirical slope of the common model as follows:

$$
G D P_{i, t}=\alpha+I T A_{i, t}+I T R_{i, t}+E X R_{i, t}+\varepsilon_{i, t}
$$

where $G D P_{i, t}$ represents the economic growth rate, IT $A_{i, t}$ represents the entry tourist arrival growth, IT $R_{i, t}$ represents the tourism income growth of each country and $E X R_{i, t}$ represents the fluctuation in foreign exchange rate.

In the common slope model, we could only see the relationship between each variable and economic growth fixed slope. We could not catch the individual difference influence of different countries. Hence, we introduced the estimation method of the differential slope to change Equation (3.1) into Equation (3.2), where subscript $j$ represents differential slope.

Wherein, $G D P_{i, t}$ represented economic growth rate; IT $A_{i, t}$ represented entry tourist arrival growth; ITR $R_{i, t}$ represented tourism income growth of each country; $E X R_{i, t}$

$$
G D P_{i, t, j}=\alpha+I T A_{i, t, j}+I T R_{i, t, j}+E X R_{i, t, j}+\varepsilon_{i, t, j}
$$

\subsection{Data and Variable Selection}

The data used for this study were from the database of World Development Indicators. We considered 11 Asian countries with international entry tourist arrivals over 500 million person-times in 2017 and used the annual data from 2000 to 2017. We took GDP as the dependent variable and the growth rates of international entry tourist arrival (TA) and international entry tourism income (TR) and the fluctuation of exchange of foreign currency to US dollars (EX) as the independent variables, as shown in Table 1. 
Table 1. Sample Data Table

\begin{tabular}{|c|l|c|}
\hline Variable & \multicolumn{1}{|c|}{ Evaluation Method } & Data Source \\
\hline GDP & Growth rate of GDP relative to last year (\%) & WDI \\
\hline ITR & $\begin{array}{l}\text { Growth rate of international tourism income relative to last year } \\
(\%)\end{array}$ & WDI \\
\hline ITA & Growth rate of entry tourist headcount relative to last year (\%) & WDI \\
\hline EXR & $\begin{array}{l}\text { Exchange rate fluctuation of currency of different country to US } \\
\text { dollar (\%) }\end{array}$ & WDI \\
\hline
\end{tabular}

Data source: Data was taken from World Development Indicators (WDI) database.

\section{EMPIRICAL RESULTLS}

\subsection{Panel Unit Root Test}

Table 2. Panel Unit Root Tests

\begin{tabular}{|l|c|c|c|}
\hline & LLC & IPS & ADF \\
\hline Variables & Level Statistic & Level Statistic & Level Statistic \\
\hline $\mathrm{GDP}_{\mathrm{it}}$ & $-5.5079 * * *$ & $-3.7084 * * *$ & $49.5590^{* * *}$ \\
\hline $\mathrm{ITR}_{\mathrm{it}}$ & $-6.1823 * * *$ & $-5.0460 * * *$ & $65.8029 * * *$ \\
\hline $\mathrm{ITA}_{\mathrm{it}}$ & $-3.2544 * * *$ & $-4.6062 * * *$ & $60.4755^{* * *}$ \\
\hline $\mathrm{EXR}_{\mathrm{it}}$ & $-5.4571 * * *$ & $-3.6312 * * *$ & $48.8214 * * *$ \\
\hline
\end{tabular}

The verification is calculated in a regression model with intercept term.

$*, * *$, and $* * *$ denote significance at $10 \%, 5 \%$ and $1 \%$ levels, respectively.

The existence of unit root in times series will cause various problems. For example, if we neglected the problem of unit root, then the statistical deduction in an empirical study would be wrong. Moreover, we standardized the variables studied in this article and found that the unit root did not exist after the unit root test, as shown in Table 2. Therefore, we could deduce that the subsequent empirical result estimation model contained certain reliability.

\subsection{Fixed-Effects Model}

In this study, we used variables, such as the growth rates of international entry tourism income (ITR) and international entry tourist arrival (ITA) and fluctuation of exchange of currency of each country to US dollar (EXR), to conduct fixed-effect model analysis on economic growth rate (GDP). From the empirical results in Table 3, we found that each variable showed a significant influence. Amongst them, international entry tourism income growth had a positive relationship with economic development, implying that when tourism income showed a growth trend, the GDP economic growth of the host country would increase relatively. Here, the fluctuation in the foreign exchange rate showing a negative relationship implied that the fluctuation in the exchange rate in the host country showed a declining trend. This situation would attract foreign tourists to consume to promote economic activity. However, tourists might also reduce unnecessary tourism consumption or change tourism route to other countries because the consumption in the destination country was higher than that of the domestic country.

Table 3. Each Variable to GDP Economic Growth: Fixed Effect

\begin{tabular}{|c|l|l|l|l|}
\hline Variables & \multicolumn{1}{|c|}{ C } & \multicolumn{1}{|c|}{ ITA } & \multicolumn{1}{c|}{ EXR } \\
\hline Coefficient & 0.1166 & -0.0889 & 0.2243 & $-1.33 \mathrm{E}-05$ \\
\hline Std.Error & 0.0184 & 0.0531 & 0.0401 & $5.69 \mathrm{E}-06$ \\
\hline t-statistic & 6.3066 & -1.6736 & 5.5903 & -2.3479 \\
\hline p-value & $0.0000^{* * *}$ & $0.0959 *$ & $0.0000 * * *$ & $0.0199 * *$ \\
\hline
\end{tabular}

Note: $(1) * * *$ and $* * *$ represent $10 \%, 5 \%$ and $1 \%$ significant level.

(2) Economic growth rate (GDP), growth rate of international tourist arrivals (ITA), growth rate of international inbound tourism receipts, (ITR), official exchange rate to US dollar (EXR). 


\subsection{Random Effects Model}

When we used the same variables to conduct random effect model analysis, we obtained results different from those of the fixed-effect model. For example, the fluctuation in the foreign exchange rate (EXR) showed a positive and insignificant influence, and the influence of exchange rate was lower than that of the fixed-effect model. This finding implied that under the random effect model, GDP economic growth had no relations to the fluctuation in the foreign exchange rate (EXR), and the fluctuation in foreign exchange rate did not have significant help to the economic development. In addition, for the influence of two variables on GDP economic growth, the marginal effect difference in the two models was different. Given that the conclusions of the two different models had different explanatory results, we used a Hausman test to judge the optimal explanatory model to explain the cause-and-effect relationship amongst our variables, as shown in Table 4.

Table 4. Each Variable to GDP Economic Growth: Random Effect

\begin{tabular}{|c|l|l|l|l|}
\hline Variables & \multicolumn{1}{|c|}{ C } & \multicolumn{1}{|c|}{ ITA } & \multicolumn{1}{|c|}{ ITR } & EXR \\
\hline Coefficient & 0.0744 & -0.1087 & 0.2312 & $7.82 \mathrm{E}-07$ \\
\hline Std.Error & 0.0134 & 0.0525 & 0.0399 & $1.93 \mathrm{E}-06$ \\
\hline t-statistic & 5.5403 & -2.0674 & 5.7899 & 0.4052 \\
\hline p-value & $0.0000^{* * *}$ & $0.0400^{* *}$ & $0.0000^{* * *}$ & 0.6858 \\
\hline
\end{tabular}

Note: $(1) * * *$ and $* * *$ represent $10 \%, 5 \%$ and $1 \%$ significant level.

(2) Economic growth rate (GDP), growth rate of international tourist arrivals (ITA), growth rate of international inbound tourism receipts, (ITR), official exchange rate to US dollar (EXR).

\subsection{Hausman Test}

In this article, we simultaneously used two models of fixed-effect and random effect to analyse the influence of each tourism-related variable on economic growth, due to different results from two different models. We conduct this process to avoid generating deviation in the estimated result when a correlation exists between intercept and explanatory variable. We used a Hausman test ${ }^{4}$ to investigate the correlation between intercept and explanatory variable and select the optimal effect model to explain the dependent relationship between variables. From the empirical results in Table 5, we determined that for the variables of this study, the fixed-effect model had better explanatory power. The growth rate of international entry tourism income (ITR) showed a significant and positive influential effect on GDP economic growth. By contrast, international entry tourist arrival growth (ITA) and official fluctuation in foreign exchange rate (EXR) variable showed a significant negative effect. Moreover, the variable data used in this study were percentage data, which possessed the flexibility concept. They were different than the raw data studied in previous literature, and thus we could further investigate the influential factor characteristic of each tourism-related variable on GDP economic growth. To confirm if different situations between countries exist in the crosssection of our fixed model, we introduced a Wald test. Through the test results, we could investigate the differential result of the tourism-related variables in the cross-section on the economic growth of different countries.

Table 5. Hausman Test Result Analysis Table

\begin{tabular}{|c|c|c|c|}
\hline Model & Chi-Sq. Statistic & Prob. & Select \\
\hline Each variable to GDP & 8.2293 & 0.0415 & Fixed Effect \\
\hline
\end{tabular}

Note: $1 . * * *$ and $* * *$ represent $10 \%, 5 \%$ and $1 \%$ significant level.

\footnotetext{
4 The model test proposed by Hausman (1978) had the same form as the variable assessment error model test. Hence, we adopted its model test method, wherein we found that our null hypothesis was an error value of intercept, which was not related to the independent variables.
} 


\subsection{Wald Test}

To inspect if the influence of the independent variable is different from that of the dependent variable in the estimator along with the individual group, we used a Wald test to understand the goodness-of-fit of the estimation value. The Wald test assumes that the null hypothesis to be tested was that the coefficient was equal. If our results failed to support the null hypothesis, then the influence of the explanatory variable on the explained variable would change along with the difference in the cross-section. At this moment, we coined the adopted estimation method as the fixed-effect model of the differential slope. In this article, after confirming that the fixed-effect model had a better condition and each explanatory variable had a significant influence, we used the Wald test to investigate whether a difference exists in the individual observation countries in the variables. From the empirical results in Table 6, we found that amongst the three introduced variables affecting GDP economic growth, two variables had inconsistent slopes in different observation countries. In the GDP economic growth model, two variables (the growth rates of international entry tourist arrival and international entry tourism income) had varied differential result across the countries, and the significant, influential situation only existed amongst some of the countries. This finding implied that each tourism variable had different meanings for GDP economic growth in different countries, and thus we should analyse the root cause of such difference. For EX fluctuation in the foreign exchange rate in the variable, it was of insignificant result in the Wald test. In other words, our results supported the null hypothesis, indicating that a common slope exists amongst different countries, and the fluctuation in foreign exchange rate had consistent importance to each country.

Table 6. Estimated Result of Wald Test

\begin{tabular}{|l|l|l|l|}
\hline Variables & ITA & ITR & EXR \\
\hline F. statistic & 2.0591 & 2.7302 & 0.9841 \\
\hline p-value & $0.0356^{* *}$ & $0.0053 * * *$ & 0.4548 \\
\hline
\end{tabular}

Note: $*, * *$ and $* * *$ represent $10 \%, 5 \%$ and $1 \%$ significant level.

\subsection{Random Coefficient Analysis}

Table 7 shows that in the influence of the international entry tourist arrival growth on GDP economic growth, two countries (Philippines and Singapore) showed significant results, and we observed a positive and influential result. This finding implied that international entry tourist arrival growth could promote the economic growth of these two countries, and economic development could attract more foreign tourists. By contrast, nine countries showed insignificant results, and the change of international entry tourist arrival growth in these countries might be slow, which could not catch up with the rapid growth in the global tourism trend. Therefore, we observed insignificance, and the influence was less than the two countries with significant results. On this basis, we generated an overall significant result.

Table 7. GDP and ITA Estimation Results- Random Coefficient Analysis

\begin{tabular}{|l|l|l|l|l|l|}
\hline \multicolumn{1}{|c|}{ Countries } & \multicolumn{1}{|c|}{ Coefficient } & \multicolumn{1}{c|}{ Countries } & \multicolumn{1}{c|}{ Coefficient } & \multicolumn{1}{c|}{ Countries } & \multicolumn{1}{c|}{ Coefficient } \\
\hline Cambodia & 0.0804 & Japan & -0.1578 & Singapore & $0.4198^{* * *}$ \\
\hline China & 0.1126 & Korea & 0.0109 & Thailand & 0.1448 \\
\hline India & 0.0858 & Malaysia & 0.1489 & Vietnam & -0.0013 \\
\hline Indonesia & -0.1837 & Philippines & $0.5904 * * *$ & & \\
\hline
\end{tabular}

Note: $*, * *$ and $* * *$ represent $10 \%, 5 \%$ and $1 \%$ significant level.

The analysis data in Table 8 showed that in the estimation result of GDP economic growth and the growth rate of international entry income (ITR), six countries, namely, India, Malaysia, Philippines, Singapore, Thailand and Vietnam, showed different random coefficients. In these countries, we observed a factorial difference between countries. For each 
country, we found a significant and positive result between GDP economic growth and the growth rate of international entry income (ITR). This result might be because the growth rate of international entry income (ITR) could increase the economic activity of that country and consequently enhance GDP economic growth. In addition, amongst the five countries with insignificant results, only Korea showed a negative influence in terms of entry tourism income, which might be related to the high emphasis of industrial and technological development in that country. The seasonal change effect of the frigid zone, which made it difficult to attract foreign tourists to visit, might also have an effect.

Table 8. GDP and ITR Estimation Results- Random Coefficient Analysis

\begin{tabular}{|l|l|l|l|l|l|}
\hline \multicolumn{1}{|c|}{ Countries } & \multicolumn{1}{c|}{ Coefficient } & \multicolumn{1}{c|}{ Countries } & \multicolumn{1}{c|}{ Coefficient } & \multicolumn{1}{c|}{ Countries } & \multicolumn{1}{c|}{ Coefficient } \\
\hline Cambodia & 0.0359 & Japan & 0.0815 & Singapore & $0.3817 * * *$ \\
\hline China & 0.1782 & Korea, Rep. & -0.0980 & Thailand & $0.3476^{* * *}$ \\
\hline India & $0.3797 * * *$ & Malaysia & $0.3014 * *$ & Vietnam & $0.1878^{* *}$ \\
\hline Indonesia & 0.1676 & Philippines & $0.1777 * *$ & & \\
\hline
\end{tabular}

\section{CONCLUSION}

Different from previous literature's focus on investigating the influence of tourism variable on the economy, we set up a GDP economic growth fixed-effect random coefficient model in this article under consistent results for Asian countries. We use this model to investigate the influence of the growth rates of international entry arrival (ITA) and international entry tourism income (ITR) and official exchange rate to US dollars (EXR) on economic growth rate (GDP). We inspected these factors by reviewing prior literature. Consequently, we could avoid the error of random sampling. We also used the random coefficient model of differential slope in this article to prove that cross-section differences exist between different countries.

From the empirical results, we obtained the following three points: Firstly, we found a common slope in the fluctuation in the foreign exchange rate, implying that each country had a consistent result of the influence of fluctuation in the foreign exchange rate on economic growth. The level of fluctuation in the foreign exchange rate also showed a negative influence on the GDP of each country. In other words, when the fluctuation in the foreign exchange rate increased, it would be inferior to economic growth. Secondly, international entry tourist arrival proved the existence of a differential slope, and we observed significant and positive influential effects in two countries (Philippines and Singapore). By contrast, nine countries showed insignificant results. However, under fixed-effect, we found a significant influence on the overall result, indicating that the influential power was quite strong in these two countries as compared with that of the other nine countries. On this basis, we generated an overall significant and influential result. Thirdly, we observed a differential slope in international entry tourism income and a significant and positive result in six countries (India, Malaysia, Philippines, Singapore, Thailand and Vietnam). This finding implied that the growth of international entry tourism income could increase the economic activity of that country, enhancing GDP economic growth. We also found insignificant results in the other five countries, indicating that tourism income did not affect the economy of that country. On this basis, we could conclude an entirely, significant and positive influence.

In line with our findings, countries with individual and significant influence could invest more in tourism infrastructure and information software policy to expand their niche for international entry tourism. Through the spreading and backflow of foreign visiting tourism arrival, they could also create a high level of continuous growth for their economy. 


\section{REFERENCES}

Aleemi, A. R., \& Qureshi, M. A. (2015). Tourism Receipts and Economic Growth: Empirical Evidence from Pakistan. International Journal of Research, 2(2), 1401-1402.

Akinboade, O. A., \& Braimoh, L. A. (2010). International Tourismand Economic Development in South Africa: a Granger Causality Test. International Journal of Tourism Research, 12(2), 149-163.

Ardra, U., \& Martawardaya, B. (2017). Tourism and Economic Development in ASEAN 19982013. Economics and Finance in Indonesia, 63(2), 114-125.

Bădulescu, A., Bădulescu, D., \& Simuţ, R. (2018). The Complex Relationship between International Tourism Demand and Economic Growth: An Analysis on Central and Eastern European Economies. Amfiteatru Economic, 20(12), 935-950.

Li, Q.Z., Luan, C.Y., \& Wang, S.X. (2019). Quality evaluation of face image based on convolutional neural network. Journal of Computer Applications, 39(3), 695-699.

Lu, Z., Gozgor, G., Lau, C. K. M., \& Paramati, S. R. (2019). The dynamic impacts of renewable energy and tourism investments on international tourism: Evidence from the G20 countries. Journal of Business Economics and Management, 20(6), 1102-1120.

Kadir, N., \& Karim, M. Z. A. (2012). Tourism and Economic Growth in Malaysia: Evidence from Tourist Arrivals from Asean-S Countries. Economic Research-Ekonomska Istraživanja, 25(4), 1089-1100.

Han, J.H., Yuan, J.X., Wei, X., \& Lu, Y. (2019). Pedestrian visual positioning algorithm for underground roadway based on deep learning. Journal of Computer Applications, 39(3), 688694.

Kilıç, C. \& Bayar, Y. (2014). Effects of Real Exchange Rate Volatility on Tourism Receipts and Expenditures in Turkey. Advances in Management and Applied Economics, 4(1), 89-101.

Kum, H., Aslan, A., \& Gungor, M. (2015). Tourism and Economic Growth: The Case of Next-11 Countries. International Journal of Economics and Financial Issues, 5(4), 1075-1081.

Nanthakumar, L., Han, A. S., \& Kogid, M. (2013). Demand for Indonesia, Singapore and Thailand tourist to Malaysia: Seasonal unit root and multivariate analysis. International Journal of Economics and Empirical Research, 1(2), 15-23.

Olabisi, E. O. (2018). Revisiting the Tourism-Economic Growth Nexus: The Case of Economic Community of West African States, Izvestiya. Journal of Varna University of Economics, 62(1), 21-30.

Yang, Q., Su, M., Wu, Y. \& Wang, X. (2019). Economic Efficiency Evaluation of Coastal Tourism Cities Based on Fractal Theory. Journal of Coastal Research, SI(93), 836-842.

Said, K. K., Luvanda, E., \& Massawe E. S. (2013). Mathematical Analysis of the Impact of Real Exchange Rate on Output Growth and Inflation: The Case of Tanzania Zanaibar. International Journal of Mathematical Research, 2(4), 23-36.

Selimi, N., Sadiku, L., \& Sadiku, M. (2017). The Impact of Tourism on Economic Growth in the Western Balkan Countries: An Empirical Analysis. International Journal of Business and Economic Sciences Applied Research, 10(2), 19-25.

Tugcu, C. T. (2014). Tourism and Economic Growth Nexus Revisited: A Panel Causality Analysis For the Case of the Mediterranean Region. Tourism Management, 42, 207-212.

Tung, L. T. (2019). Does exchange Rate Affect The Foreign Tourist Arrivals? Evidence in an Emerging Tourist Market. Management Science Letters, 9(8), 1141-1152.

Wang, Y. S. (2009). The Impact of Crisis Events and Macroeconomic Activity on Taiwan's International Inbound Tourism Demand. Tourism Management, 30(1), 75-82.

Yalçinkaya, O., Daştan, M., \& Karabulut, K. (2018). The Effects of International Tourism Receipts on Economic Growth: Evidence from the First 20 Highest Income Earning Countries from Tourism in the World 1996-2016. Montenegrin Journal of Economics, 14(3), 55-71.

Yazdi, S. K. (2019). Structural Breaks, International Tourism Development and Economic Growth. Economic Research-Ekonomska Istrazivanja, 32(1), 1765-1776.

Zhang, X.L., \& Zhang, R. (2018). Research on object identity aware network traffic technology based on structured learning in multi-target tracking. Journal of China Academy of Electronics and Information Technology, 13(3), 284-290. 